New Library World, 105 (1196/1197) January 2004, 33-46 [ISSN 0307-4803] [online]:

http://www.emeraldinsight.com/Insight/viewContentItem.do;jsessionid=15312C711C4089A AE9F4D2F019702FCD?contentType=Article\&contentId=860174 [Accessed 17 January 2005]

(Also published in: 'Coping with continual change - change management in SLIS': proceedings of the European association for Library and Information Science and Research (EUCLID) and the Association for Library and Information Science Education (ALISE) joint conference, Potsdam, Germany, 31 July - 1 August 2003; edited by Linda Ashcroft. Bradford: Emerald, 2005. ISBN: 1-84544-156-7)

\title{
Impact evaluation, professional practice, and policy making
}

\author{
Ian M. Johnson, Dorothy A. Williams, Caroline Wavell, and Graeme Baxter
} Aberdeen Business School, The Robert Gordon University, Garthdee Road, Aberdeen AB10 7QE, Great Britain (i.m.johnson@rgu.ac.uk)

\begin{abstract}
This paper examines the relationship between research into the evaluation of the impact of library and information services, policy making in the field, and professional practice and education. The paper first summarises the background to a recent critical literature review undertaken on behalf of Resource: the Council on Museums, Archives and Libraries. The review was intended to identify any published evidence that Museums, Archives and Libraries are making a contributory impact to developments in the British Government's key policy areas. Except in the field of learning, little supporting evidence was found. Methodological weakness undermined the validity of much of the related work identified by the review. After considering approaches to ensuring the impact of research on policy making, including a more appropriate publication strategy and greater face-to-face dialogue, the paper discusses the attitudes of LIS practitioners towards academic research and the need for closer collaboration. Finally the paper speculates on some of the implications for LIS educators in developing future researchers better equipped to identify the contribution that libraries make, and more effective in influencing policy makers.
\end{abstract}

\section{Introduction}

Michel Menou, who has worked on some of the most high-profile international attempts at impact evaluation, has defined the need for evaluation of the impact of library and information services as meeting 3 principal requirements:

- the scientific need to understand what information is and how it affects human behaviour;

- the managerial need to prove information is a critical resource;

- the political need to provide a rationale for policies and justify investments and thus to secure popular support (Menou, 2001).

The first of the aims outlined by Menou acknowledges the potential for undertaking both pure and applied research that is available to the LIS research community, and for blending these 
approaches. The other two aims associated with policy-relevant research and its utilisation are more pragmatic in their nature, and more obviously of interest to the practitioner. The paper aims to elaborate on some of the latter issues. It takes as its starting point a recently undertaken review of research into the impact that libraries have on key British government policy areas, and considers other recent research into policy makers' and practitioners' attitudes towards research, before discussing some of the implications for teaching and research in the Schools of Librarianship and Information Sciences.

\section{Research, library management, and policy making}

The willingness of organisations to support their libraries and information services, particularly in periods of austerity, has been a recurrent concern of the profession. The factors that are believed to impact on the demand for library and information services have therefore been frequently described in the profession literature. They include:

- growth in the client population;

- development of educational provision;

- increasing literacy;

- scientific and technological change;

- increase in the volume of published media and changes in the form of these outputs (adapted from Lewin, 1993).

Most of these appear easily demonstrated; many are quantifiable. The assumed impact of these factors on the demand for library and information services have been regularly used by the profession to promote growth - or at least to try to preserve the status quo, and they have regularly been the subject of research in the form of data gathering and associated commentary. Researchers and practitioners have been distracted from any debate about the merits of these factors in supporting the case for funding by the subordination of library and information services to organisations of so many different kinds, which has made it problematic to collect data that could be used to benchmark progress. However, it seems clear that the benefits of information availability and use are not fully demonstrated by the simple demand factors typically advanced by practitioners in support of their case for funding. Moreover, the causes of low budgetary allocations to libraries and information services appear more complex than simple links to organisations' circumstances would suggest. It is arguable that it is more meaningful for policy makers to be able to evaluate the contribution that libraries and information services make to the overall changes that result from achieving their organisation's goals.

In recent years, successive British governments have sought to achieve better management of publicly funded services through monitoring the delivery of the government's policy goals. Since its election in 1997, the current Labour government has accelerated this trend in two ways. First, it has made clear that cases for extra spending will only be considered when there is a clear strategy that delivers value for money. Secondly, it has emphasised its wish to be seen as a modernising government characterised by the pursuit of evidence-based policy.

This approach and the increasing demand for evidence of outputs and outcomes are not being felt solely in the public services, nor only in Britain. A recent survey of business information professionals in the U.S.A. noted their concern to improve the business impact of their services and be recognised for adding value to enable the organisation to meet its goals (LexisNexis, 2003). There is, therefore, a clear and widespread need for better understanding of the economic benefits that stem from libraries and information services, as well as the extent to which they contribute to achieving broader social objectives. 
Resource was established in April 2000 by the British government to work with and for museums, archives and libraries, providing strategic leadership, promoting innovation, developing capacity and acting as a powerful advocate,. It is a 'non-departmental public body', funded by a grant-in-aid from the Department of Culture, Media and Sport, but with a wider remit than the sponsoring Department. ${ }^{*}$ The government has identified a number of social, educational and economic policy areas for priority action, and Resource therefore needs to be able to demonstrate the impact that the sector ${ }^{\dagger}$ has on them in order to leverage additional support for these agencies from the relevant government departments. Resource is, therefore, particularly interested in encouraging the sector not only to develop and use impact measures to manage services but also to demonstrate the impact of those services on endusers and non-users in a way that is meaningful to politicians.

Resource took over the funds previously used by one of its predecessor bodies, the Library and Information Commission, to support research activity in the field. In the present environment, there is increasing pressure on government departments and on agencies such as Resource to, inter alia,

- increase the efficiency and effectiveness of research (National Audit Office, 2003);

- make difficult choices in the allocation of scarce resources for research; and

- integrate "classical” research policy with broader socio-economic targets (Kuhlman, 1999).

Resource's indication of its intention to support only research relevant to government policy making was not well received by the LIS academic research community at that time. Although the funding available from the Commission and its predecessors had been declining for years, the absence of any significant alternative government funds to support the broader potential range of research in the field was a significant concern for an academic community facing regular national assessments of its research activity.

The general approach that Resource is taking is:

- establishing what the needs are for information about impact - in particular, the government's needs and the sector's;

- establishing what evidence about impact already exists and how useful it is;

- identifying gaps in existing provision;

- developing and, where practical, implementing methods and mechanisms for filling those gaps;

- helping to ensure that the relevant data are pulled together to present a coherent, workable, consistent and sustainable system that satisfies stakeholders - users, staff and funding bodies (Resource, 2003).

\footnotetext{
* There is no single government Department responsible for oversight of publicly funded libraries in the U.K. The Department of Culture, Media and Sport superintends the British Library and the public library services. The Department of Health supervises the increasingly important information and knowledge management activities of the National Health Service. The Department for Education and Skills is responsible for policy on school, college and University libraries, but employs no specialist professional adviser for that purpose. The Department of Trade and Industry might seem the natural locus for any activity to encourage the private sector in Britain to manage its information resources and make more effective use of them, but to date has confined its interest to regulatory matters such as copyright and data protection.

$\dagger$ In the terminology adopted by the British government, 'sector' is used to denote museums, archives and libraries collectively, and ‘domain’ denotes museums, or archives, or libraries as individual types of organisation.
} 
Impact evaluation is, however, a complex issue, not helped by the fact that museum, archive and library researchers do not make consistent use of the terms 'outputs', 'outcomes' and 'impact', and the distinction between them is not fully understood by the professions. In any study of the impact of information, the purpose of providing the information needs to be the focus rather than the nature and scale of the information provision itself. Outputs are the direct service product of combining inputs and processes. They provide a measure of efficiency and have traditionally been measured quantitatively (for example: number of services provided and number of people provided for, numbers of books issued, number of reference enquiries answered, time taken to process raw materials). Outcomes are the positive or negative engagement with planned outputs by an intended or unintended user. Outcomes can be short or medium term (for example: book read, interaction with a website, answer to enquiry received). Impact is the overall effect of outcomes and conditioning factors resulting in a change in the state, attitude or behaviour of an individual or group after engagement with the output, and is most easily expressed as 'Did it make a difference?'

\section{Available evidence on impact}

As a first step, Resource commissioned Information Management Associates to undertake a critical evaluation of the projects that were funded under the former Library and Information Commission's Value and Impact Programme. They found that those projects, whilst generating a significant amount of useful information, did not really provide compelling evidence of impact (Streatfield and Markless, 2002). Subsequently, to relate to developments in the government's education agenda, two projects examining the impact of school libraries were carried out for Resource by a team led by Professor Dorothy Williams at the Robert Gordon University (Williams et al., 2001; 2002). They found that there was a body of research supporting the view that school libraries can have a positive impact on academic achievement, particularly at the primary and early secondary level. However, there was no clear evidence to differentiate the contribution made to learning by the various models of school library provision to be found throughout the U.K.

These led to the award of a further contract to carry out a broader project that sought to examine the sector as a whole (Wavell et al., 2002). The aim of this study was to synthesise the available evidence in order to provide a coherent picture of the impact that museums, archives and libraries have had in key government priority areas, and to support Resource in developing strategies for assessing the long-term impact of the three domains. It built on a considerable body of work that has already established the need to consider more closely the outcomes of services and activities, as opposed to traditionally measured outputs. As well as pulling together what evidence already existed, the project also assessed the methodologies that have been used so that future impact evaluations could be based on tried, tested and appropriate methods. The methodology used for this study was a desk based critical review of the literature of impact evaluation in all types of museum, gallery, archive, and library, concentrating mainly on evidence from the U.K. over a retrospective period of five years. Some significant work outside that period or outwith the U.K. was also noted. For the purpose of this paper, the focus will be solely on evidence about the impact of the library domain.

Evidence from various research projects examining social impact indicated that libraries do make a positive impact in supporting personal development, social cohesion, community empowerment, local culture and identity, and health and well-being. The most compelling evidence was in the area of personal development, if only because the immediate outcomes 
are more easily identified and less problematic in terms of establishing causality. However, the evidence presented in the social impact studies varied in the extent and rigour with which it was reported. The literature included evidence in the form of project cameos, short anecdotal quotes and brief accounts of engagement with specific groups in the community. The exploratory nature of these evaluations does more to demonstrate potential for a wider range of social impacts than provide consistently convincing results. Moreover, there are still substantial differences between studies in the way impact is described and presented, which makes comparison and collation of evidence difficult. There is a need for further investigation to establish an agreed set of areas of potential social impact and indicators that can be used to identify impact. Work by Matarasso (1998) has already influenced researchers, and would appear to provide a starting point for establishing a coherent way forward.

Learning is closely related to social and economic impact in terms of underpinning lifelong learning, health and well-being and business information needs. There were a number of empirical studies examining the relationship between libraries and learning during the period under review, indicating that libraries had made a positive impact on enjoyment and choice of leisure reading material, on reading development in young children, on academic achievement, particularly in terms of acquisition of language and ICT skills and information literacy, and in terms of acquisition broader aspects of learning, such as increased motivation for learning, self-confidence, independence. All the studies examined reflected the complexity of the learning process, the difficulties of isolating the impact of the library from other significant influences, and the challenges in establishing causal relationships. Again, however, the evidence presented varied in rigour and did not establish the overall impact on a clearly defined sample. The relationship between learning and use of libraries has been the subject of more extensive research than social and economic relationships. Nonetheless, there are still gaps in our understanding of the relationship between the use of libraries and its longterm impact. Most evaluations have concentrated on particular projects or new services, and there is a need for more examination of the ongoing impact of core services.

The majority of the research into the sector's economic impact within the timescale of this review was international and concentrated on the arts and cultural industries in general. Research has also concentrated on the public sector and major public spending initiatives. More than 10 years ago, Martin Carnoy (1992), Professor of Education and Economics at Stanford University, drew from case studies of experience in Asia that economic growth is dependent on the knowledge and information that in turn depends on effective investment in utilising information-based technologies and in an education base that provides the human resources to apply them, but said nothing about the impact of the ability to use the information itself. Since then, there appears to have been little investigation of the evidence for the economic impact of information, at least evidence that has appeared in the public domain from private or independent organisations such as corporate libraries. While there is some positive exploration of the impact of information services on the business community, this is limited and has not been related to areas of public or government interest, for example how library services impact on inward investment in a particular area. Research into the economic impact and value of business information, or into the relationship between public libraries and town centre regeneration, is also limited. However, research into the economic impact conducted in public libraries in the U.K. claims evidence of impact in terms of direct and indirect impact on job creation, respondents' perceptions of economic benefits to the local community, impact of visitor spending in town centres, and the impact of business information provision on business success. The research in this area is at the stage of 
investigating possible approaches to measuring impact, and demonstrates potential rather than actual impact (Warr, 2003). While some studies have been based on economic impact or cost benefit analyses and result in statistical or monetary evidence of impact, other studies have used qualitative and quantitative approaches where economic impacts are not necessarily defined in monetary terms. Many of these studies have used relatively complex analytical techniques, and have been conducted by economists rather than by information professionals. While a number of naturally occurring indicators for the social and learning impact of the sector have already been identified, economic indicators are still being explored.

Overall, the evidence indicated that a great variety of approaches have been used for assessing libraries' impact. None are suitable for all situations and all have advantages and disadvantages. In addition, at present, project evaluations are the most readily available source of evidence of social and learning impact. They provide a useful means for practitioners to raise awareness of what can be achieved and provide understanding of how it can be achieved. In this they provide a foundation for organisational management. These findings were broadly confirmed by a separate study, which concluded that applied research used to resolve practical issues predominates in LIS research (Turner, 2002). However, the quality of these evaluations varies tremendously, and they are more focused on the project's immediate outcomes than any longer-term impact. They tend to be non-cumulative and descriptive reporting, with results that are difficult to replicate and rarely generalisable to a variety of settings. They may even be distorting the true picture of impact or deflecting attention away from more significant areas of impact. More thoroughly prepared, compatible, and long-term studies of core services are necessary to provide a full picture of the impact of libraries and information services.

It is acknowledged that long term impact may be diffuse, difficult to identify and to conceptualise. Some small comfort may be drawn from the fact that LIS is not alone in its difficulty in demonstrating evidence for its contribution. A recent study of the contribution that business education makes to the U.K. economy commented that:

"A very large proportion of the literature on evaluation, whether in relation to higher education, or training and management development, describes what should be done rather than reporting on evidence actually collected.” (Hirsh et al., 2002)

This paper is, however, not so much concerned with the availability of evidence for libraries' impact, nor with the research methodologies per se, as with certain implications of the project's results.

\section{Impact and policy making}

Historical, bibliometric, and technological perspectives dominate research in the field of librarianship and information sciences. There is a substantial range of methodologies testifying to a long-established interest in evaluating the operational efficiency of library and information services, but equally a dearth of economic, educational and political research that focuses on the measurable returns to society from investment in library and information services and the promotion of these values (Johnson, 1994). There is ample scope for impact evaluation across the whole range of libraries and information services, examining roles wider than those investigated at Resource's request. Those relevant to government policy making might include the effective use of information in, for example:

- promoting scientific and technological change;

- raising standards of public health; 
- preventing environmental degradation;

- fostering good government.

However, the impact studies undertaken for Resource have highlighted the fact that research aimed at evaluating the role of library and information services in support of other disciplines lacks a conceptual framework and an accepted body of methodologies. This possibly has significant consequences, particularly in limiting the perception by citizens and policy makers of the role that information does or could play in promoting social and economic well being.

In parallel with any increase in relevant research activity, more attention needs to be given to dissemination activities. The influence of impact research on policy making seems more likely to be assured if:

- channels could be developed to communicate with the broadest possible audience, including the policy makers;

- the knowledge gained from research could be presented in different versions to meet the needs of the various potential target audiences; (Water Engineering and Development Centre, 2000)

Whilst there have been any number of recent, experientially-based publications outlining techniques for lobbying LIS policy makers, there appears to be no substantial body of evidence about the links between research evaluating the impact of libraries and policy making in the field. There appears to have been no follow-up to work by Craghill and Wilson (1987) examining the impact of information research, which began to touch on this area, although focused mainly on assessing the more tangible impacts on professional practice and on the curricula. We must therefore, initially, look to other disciplines where research into impact evaluation has been undertaken - education, international development assistance, and innovation transfer between universities and firms - for evidence as to how such research could contribute to policy making.

Researchers must first recognise that policy changes occur on different scales, and possibly incrementally. First order change involves minor adjustment to policies, second order change introduces limited experimentation, and third order change involves a radical shift. Even having accepted that research may influence policy, such changes in policy cannot always be easily attributed to specific pieces of research; instead, it would be more legitimate to contend that a range of research inputs feed into and help shape the thinking (Coe et al., 2003). Moreover, it also has to be recognised that the influence of researchers diminishes as the policy makers progress from taking advice to designing and implementing proposals.

Parallels with research-based industrial innovation suggest that a critical success factor appears to be the capability of the policy makers to find, select and absorb the knowledge relevant for decision-making. Policy makers are themselves generally well educated, information literate, and receptive to rigorous research and analysis, but may have limited capacity to understand the strengths and limitations of research findings in an unfamiliar discipline. Clearly, more thought is needed about how research results can be effectively communicated to them.

Saywell and Cotton (1999) commented that the difficult process of knowledge sharing means that research results are often neglected, and a significant amount of research is never communicated beyond the immediate circle of interest. A report by RAND Europe on how 
British government Departments commission, manage and use research, compiled on behalf of the UK National Audit Office, also observed that:

"dissemination of research findings is not sufficient to ensure that research findings are used to improve service delivery and to inform policy.” (National Audit Office, 2003)

Establishing a direct correlation between the results of research and seemingly related policy developments is complicated by the

"indirect and often intangible nature of many knowledge flows." (Scott, 1999)

Nonetheless, however difficult it may be to overcome these challenges, research results are likely to be sidelined unless the researchers understand how the knowledge flows within their field and communicate the results and their conclusions within the channels that the policy makers regularly use.

What appears important is to ensure the people involved do actually receive the information so that it can seep into the policy making processes. The main problem appears to be that the interface between researchers and policy-makers is probably not correct. Factors that seem most likely to enhance interaction between researchers and policy makers include:

- the relevance of the research to the policy makers' concerns;

- the extent to which the research group actually publicises its research;

- spatial proximity, or tolerable costs for telecommunications or travel, to facilitate interpersonal communication;

- the research group's previous experience in interacting with policy makers;

- established patterns of interaction.

Researchers need to recognise that extra effort is needed to transfer the results of their work into the policy making arena, and it is essential that there should be an effective strategy for the communication of the results. The means of research dissemination commonly deployed by researchers in other disciplines to try to communicate the results of their investigations to policy makers broadly fall into six categories:

- publication of journal articles and working papers;

- producing policy briefs to share findings with policy-makers;

- press releases and conferences, targeted at the general media as well as the professional press

- $\quad$ specially organised conferences and workshops;

- dissemination through policy networks;

- lobbying influential people and groups (Coe et al., 2003).

Are we sure that policy makers in the LIS field are not having to be proactive in seeking out information, instead of having it presented in relevant forums and user-friendly formats? The traditional approach to disseminating LIS research has been to assess its scientific and technological excellence by peer reviewing and to publish it in scholarly journals. However, there appears to be a negative correlation (that needs to be tested) between the traditional academic approach to dissemination and the influence of research on policy making. It may not be sufficient to write an excellent paper, expect that that it might be read in policy circles, and hope that something will then happen. As one commentator has bluntly observed:

"if you want to influence policy, writing for peer-reviewed journals and attending international conferences can't be your main focus”. (Coe et al., 2003)

This is already appreciated by pressure groups- and some are already attempting to influence the future development of libraries - whose arguments may receive considerable attention 
despite in some cases (e.g. Leadbetter, 2003) a very limited acquaintance with the field and little evidence to substantiate their arguments. Effective dissemination of meaningful research results is critical to deflect such incursions into the policy making process. Weaknesses in the communication of the results of sound research evaluating the impact of libraries and information services may have significant detrimental repercussions for the domain.

The percentage of all LIS research that gets into a variety of media is probably very low. However, publication - even in a variety of media - is not enough.

"What is considered as new knowledge, very often is the new combination of already existing pieces of knowledge. The combination occurs through personal interaction and communication processes between individuals.” (Schartinger et al., 2002)

This suggests that lessons from LIS research could be fed into ongoing policy development, provided that channels of communication and relationships are developed that can build trust over time. The duty of the researcher, according to one policy analyst, is therefore to

"Figure out who has a voice, interest. Find out who's open to persuasion. Get heard in the right corners”. (Coe et al., 2003)

However, workshops planned by the research community and specifically geared towards the needs of LIS policy makers appear to be the exception rather than the rule, even though personal contacts and direct interaction could stimulate the adoption of new knowledge in policy making. Similarly, setting up policy networks appears an almost unknown approach in LIS, yet they could stimulate face-to-face dialogue between researchers and policy-makers.

Such a medium is necessary to review the potential impact of research on policy, as:

"The formalisation of the interaction is a different approach to ensure a sufficient level of trust and to reduce uncertainty." (Schartinger et al., 2002)

Nonetheless, it is also important to recognise that more widespread dissemination of research results is not itself sufficient to result in more informed policy making. Policy makers reflect the values of the groups they represent in the issues they chose to address, the solutions they consider, and in the trade-offs they are willing to make (Bird, 2003).

"There is no linear relationship between research and policy making; policy makers are influenced by other factors such as budget considerations, demands of the electorate, their own personal experiences, as well as international pressures - none of which may have any kind of evidence base”. (Coe et al., 2003)

Whilst in political priority areas, such as those identified by the British government, researchers may not be able to exert exclusive influence, they may be able to lead a debate in particular directions through the injection of ideas backed by evidence of impact.

Further, as Peers and Johnston (1994) noted, ideas interact with power to produce policy, and: "pursuit of good practice is not a democratic process... not all voices are heard and even when they are, they are inevitably weighted in terms of influences."

Clearly, any dissemination and lobbying activity needs to take account of a diversity of target constituencies to ensure that a broad representation of the key individuals and organisations are engaged in a dialogue on the issue in question, so that they come to recognise and value the contribution that information and information services are making toward achieving progress in this area. As well as closer collaboration with the funding agency or policy makers in undertaking impact evaluation research to ensure that the results are fully informed and meaningful, researchers must acknowledge the importance of communicating the results to the other stakeholders - the public or other potentially influential groups, for example, the 
service planners and implementers, and the prospective beneficiaries of the service - who have an interest in the results of the research and who may have an influence future developments (Murphy and Rubiano, 1999). But, "to be effective, research has to be invoked by people with the power to make their view dominant". Thus, for research to be influential, those who promote its findings must seek to identify and work with the people who initiate the motivation for change (Coe et al., 2003). Researchers willing to engage with policy making may therefore find it efficacious to identify and recruit powerful intermediaries, such as elected politicians, to promote their arguments.

\section{Practitioners and research}

Resource's approach to evaluating impact compels the LIS community as a whole to confront the relationship between research, policy making, and the development of the profession. Most library and information professionals are convinced that they make a useful contribution towards the achievement of the broader organisation's goals, and the importance of bridging the gap between research, practice and policy making has been increasingly widely recognised in recent years. For example, participants in a seminar on impact strategies for librarians in developing countries recommended that librarians should be prepared to show, in a positive and appealing manner, the specific results of previous achievements, the costs incurred and the benefits gained (IFLA, 1995). Most researchers are equally anxious to ensure that their work influences policy and practice. However, the longstanding debate about the contribution that LIS research makes to professional practice serves as a distraction from, if not as an obstruction to devising appropriate strategies for achieving these goals. Certainly, one interpretation that could be placed on responses to the recent study by McNichol and Nankivell (2003) suggest that researchers' attitudes to wider dissemination of their work are to some extent coloured by complacency or by a fear of rejection.

There are, nonetheless, practitioners who are convinced of the value of research in underpinning service development. The sector-wide study of impact evidence undertaken for Resource identified a body of published research that had been undertaken by practitioners to evaluate developments in their services. Some similar research may have been overlooked because of limited distribution of reports, or poor dissemination of results. In addition, the study established that there are public librarians in the U.K. who belong to a benchmarking group that is subscription-based and who exchange information that is not made publicly available (Institute of Public Finance, 2003). In New Zealand, it has been noted that academic librarians seeking to resolve workplace problems similarly tend to rely on professional networks to exchange information (Turner, 2002). Such activity may be given a guarded welcome in that:

"If research is absent there is no profession, but only an occupation grounded in techniques, routine and common sense." (Juznik and Urbanija, 2002)

However, the demands of professional practice seem likely to focus practitioner research on reviews of current projects and practices, but

"Research informing policy is generally more formative; that required to inform planning and practice is more operational”. (Coe et al., 2003).

A shift in emphasis towards the evaluation of policies on core services requires a corresponding shift in professional thinking. The practitioners may, however, fear that effective evaluation will show that their service is making only a limited impact, encouraging their organisation to reduce the library budget, rather than seeing it as a potential opportunity to justify strategic changes. 
Moreover, the failure to disseminate the results of practitioner research inhibits questions about the robustness of the methodology and data, and about the generalisability of any conclusions drawn from it. Developments in policy cannot be assumed to follow the implementation of concepts, technology, materials or services by one library or information service or even their subsequent adoption by others. Policy implementation has to be preceded by an evaluation of general relevance and then accomplished through adaptation to local circumstances.

There do, however, appear to be barriers to the acceptance by practitioners of independent research results.

“.... Information by itself does nothing. People must be receptive to the information."

(Zielinski, 2001)

A low regard for LIS academic research in the practitioner community was noted in two recent studies of practitioner attitudes to research (McNichol and Nankivell, 2003; Turner, 2002). McNichol and Nankivell (2003) also noted a reluctance amongst the LIS community (including the LIS academic community) to acknowledge relevant work undertaken by researchers who were not themselves members of the LIS community. LIS practitioners are, however, not alone in their perception that:

"Academics are often isolated from reality; they deal in ideal situations which do not exist".

(Coe et al., 2003)

\section{Implications for professional education}

If LIS practitioners do not value and make use of academic research results, how can we expect policy makers outwith the profession to pay any attention to it? Practitioners' attitudes may have also influenced the policy makers to give a low priority to allocating funding for LIS research. The consequent lack of continuity in research funding has led to one-off rather than on-going approaches to impact evaluation, resulting in a 'Catch 22' situation in which there is little opportunity for the development of new and better research approaches that might produce more substantial, credible and acceptable evidence of impact. This, in turn, will inhibit the development LIS service organisations.

There is little merit in increasing research into the impact of libraries and information services if the results are not transferred into the policy making process. It must be accepted that the main responsibility for achieving a better interface between researchers, practitioners and policy makers lies with the LIS research community, who must understand the policy making process, the information processing habits of the policy makers, and the political environment. The inter-relationship between research and policy making therefore has significant implications for the Schools of Librarianship and Information Sciences in the U.K. (and elsewhere) in terms of both programme orientation and research related activities, which may not have been fully acknowledged in any present interest in evidence-based practice.

The test for the Schools of Librarianship and Information Sciences is whether they can stimulate in another generation an enthusiasm for meeting the "new conceptual challenge" of impact measurement (ETAN, 1999), and indeed whether they have the skills and commitment to undertake the range of teaching and research that is required - alone or with partners from other disciplines - to develop the awareness and skills that are required investigate impact and to use the outcomes to influence policy making. 
Special training appears to be needed for future researchers, both academics and practitioners, as it seems that knowledge of their professional discipline alone is clearly not sufficient.

Participants in an IFLA seminar called for "a syllabus that would help libraries to influence decision makers through, e.g. strategic planning, greater familiarity with the economics of information, and lobbying activities.” (IFLA, 1995) How can we ensure that future practitioners are able to make a sound evaluation of the sociological and economic underpinning of our professional activities? How can we ensure that the professional curricula adequately recognise the significance of political influences? There are, of course, a number of factors that inhibit the development of relevant teaching:

- students' and employers' adverse reactions to time and effort being allocated to something that they perceive as of marginal significance;

- limitations in the expertise of staff and students to work in these topics;

- limited resources to support related research.

A key issue is to get students - the future's researchers, practitioners, and employers - to embrace new thinking,

"But if it's not going to be part of the examination, they're not interested". (Coe et al., 2003) However, education research suggests that students' attitudes are more likely to be shaped by their perceptions of the prospects of bettering their income and working conditions than by any simple change in the curriculum. Given the present weak state of the evidence linking the activities of libraries and information services with organisations' performance, it is difficult to assume that a successful case can easily be made for additional resource inputs to the domain without more and better research. Practitioners are committed to the development of their services, and seem more likely to be interested in research that offers them the opportunity to do so (McNichol and Nankivell, 2003). It should not, therefore, be difficult to motivate them to develop the skills required to improve the quality of impact evaluation research and the relevance of the evidence drawn from it.

Craghill and Wilson (1987) did demonstrate that the results of research do flow into the curriculum. The challenge in introducing students to impact evaluation and policy making is that much of the impact research in the discipline area undertaken to date is methodologically suspect, and the links between research, policy making and professional practice have barely begun to be explored. Where then can the content and expertise for enhancing the curriculum be found?

It is generally accepted that a multi-disciplinary approach can deepen understanding of the way complex issues can be tackled (Dror, 2003). Colleagues in other disciplines have in some cases made significant progress in developing their understanding of both impact evaluation and influences on the policy making process, as well as means of communicating these concepts to students. It should be possible to draw on their experience and expertise, but regrettably many Schools of Library and Information Sciences have in the past been isolated from other academic disciplines. Can we afford to rely on the chance of employing teachers who are graduate librarians but whose first degree was in one of these other areas? Building relationships with colleagues who are experts in other disciplines to involve them in delivering a novel curriculum may be a preferable solution. It is not necessarily easy, but may contribute to the development of new insights into the operation of our profession.

It seems essential to provide future researchers and practitioners with a clearer understanding of policy making, to appreciate, for example, how the policy making process is politicised. A dominant ideology - of whatever persuasion - often means that governments - and other 
organisations - are reluctant to hear about options and alternatives, even if they are well researched and evidence-based. However, on occasions when pressure from the media and public opinion increases, they may seek to suggest that their policies are based on scientific research and advice (Rojo, 2002). But, research may be commissioned in an attempt to provide evidence to support or oppose political positions, rather than to provide a genuinely objective exploration of solutions to a problem or issue. Researchers are also often useful to the bureaucrats and politicians because

"they can be used to delay the implementation of politically unpalatable but necessary policy solutions". (Coe et al., 2003)

Equally, researchers need to recognise that policy makers may see independent research initiatives from one of two perspectives:

"One, incremental research that identifies attractive outcomes, for example by emphasising value for money options; and two, oppositional research, where you are pressurising government to do better." (Coe et al., 2003)

Researchers, if they want to achieve impact on policy makers, must learn to recognise and adapt to these manifestations of political priorities. Clearly, LIS students need to be not only alerted to the politicised nature of the research environment in which they might subsequently be working, but also prepared for working effectively within it. In the field of political science, for example, there is already a large body of research evidence on the representation of professional interests within governments and international agencies ( e.g. Greenwood, 1997), a theme which has formed an element of The Robert Gordon University's Masters degree in Information Analysis for the past 10 years. The rationale underpinning this course is that researchers who understand policy formulation and implementation are more likely to produce recommendations that are meaningful and susceptible to being implemented without distortion. Part of the course is taught by a political scientist. Another part is taught by financial strategist to give students an understanding of the business perspective on the use of research in decision making.

It is noticeable that LIS R\&D policy and funding is becoming increasingly international, through e.g. the World Bank InfoDev Programme, the European Commission's research and development programmes ${ }^{\ddagger}$, and the NSF-JISC collaboration between Britain and the U.S.A. ${ }^{\S}$ There are also increases taking place in intra-regional activity, in Europe at least. This expansion of international collaborative research is being implemented at a time of, and perhaps at the expense of, contraction in support for local/national activity, if not in real terms then at least in relation to increases in the demand for research funds and the capacity to utilise them. However, social, political, economic and technological globalisation makes it increasingly important to look more globally. In an increasingly global society there is a need not only to address common technological problems, but also to acknowledge and address the increasing commonality of socio-economic problems (Kuhlman, 1999). As theory influences practice and practice influences theory, countries' historical specificity is waning (Coe et al., 2003). It seems generally accepted as being valid and important to make comparisons with best practice or experiences in other countries. The challenge is to consider how things are different and therefore what are the relevant aspects. For the LIS teaching institutions, this suggests that an element of internationalisation needs to imbue the curriculum to enhance

\footnotetext{
‡ ALFA, AUNP, MED-CAMPUS and TEMPUS are programmes that support the development of Universities in Latin America, Asia, the Mediterranean region, and Eastern Europe. Similar programmes support a range of collaborative activities with Universities in Australia, Canada, Japan, and the U.S.A.

${ }^{\S}$ The U.S. National Science Foundation and the (British) Joint Information Systems Committee support a programme, 'Digital Libraries in the Classroom', which draws on best practice in the creation and delivery of content.
} 
students' critical and analytical thinking, and that it will be increasingly important to ensure that future practitioners as well as researchers will need to develop the ability to apply comparative methodologies to develop their understanding of topics. In today's environment, it also points to the increasing potential for international collaboration between Schools of Library and Information Sciences (Johnson, 2000). These are not new concepts. Marco elegantly discussed the rationale for internationalising education for librarianship some thirty years ago (Marco, 1977).

The broader spectrum of research activity implicit in developing means of understanding the interaction between the political process and support for the development of library and information services, may also open the door to new sources of funding. At a conference on European library and information research policy, Haynes pointed out that the sources of funding drawn on for library and information research in Europe were predominantly those made available by Ministries of Culture (Haynes, 1996), and the participants concluded that LIS research was not generally recognised as a bona fide research area by those organisations entrusted with overall responsibility for scientific research (Haynes and Cotton, 1996). However, in Britain at least, the research activities of some of the Schools of Library and Information Sciences are now beginning to attract funds from the government's Science Research Councils, as well as from foundations focused on social concerns.

A recent commentator has observed that:

"A body of basic research, widely agreed to be lacking in LIS, defines a profession, and is fundamental to its advancement." (Turner, 2002)

Whilst the criticism in this statement might not be wholly justifiable, reflecting on the outcome of the impact studies undertaken for Resource strongly suggests the need for a greater emphasis on impact research if the profession is to make and be seen to make a significant contribution to social and economic development. For the LIS research community, both academics and practitioners, the immediate concerns must be not only to determine meaningful and measurable indicators of the impact of libraries and information services in different fields, but also to investigate how the impact of different pathways for dissemination to practitioners and policy makers in the field can be evaluated and improved, so that the results of their research can be seen to play a more effective role in strengthening library and information services. A strategic approach to these issues seems likely to be beneficial, offering - in the medium to long term - deeper recognition for the impact of libraries and information services in society, and increased funding for the research needed to explore, evaluate and enhance their contribution. At the request of Resource, the project team at RGU privately made a number of suggestions for strategic actions that Resource might consider adopting to take forward its work in this area, and its plans will emerge in due course.

\section{REFERENCES}

BIRD, S. 2003. Communicating scientific advice to the public. The IPTS Report, 72, March, 20-24 CARNOY, M. 1992. Universities, technological change and training in the Information Age: the Asian case. Washington, D.C., U.S.A.: The World Bank, Economic Development Institute COE, J., LUETCHFORD, M., and KINGHAM, T. 2002. id21: tracking routes towards impact. Brighton, U.K.: University of Sussex, Institute of Development Studies, id21 Development Research Reporting Service. Viewed on the Web on 3 June 2003 at URL - http://www.id21.org/id21-info/impact.html CRAGHILL, D. and WILSON, T.D. 1987. The impact of information research. Sheffield: Department of Information Studies, University of Sheffield. (British Library Research Paper 20) 
DROR, Y. 2003. Science advice: tasks, preferable features, impact assessment. The IPTS Report, 72, March, 13-19

ETAN EXPERT WORKING GROUP. 1999. Options and limits for assessing the socio-economic impact of the European RTD programmes. Brussels, Belgium: European Commission. (EUR 18884) Viewed on the Web on 3 June 2003 at URL - http://biosociety.cordis.lu/Docs/Doc/ETAN_document.doc

GREENWOOD, J. Representing interests in the European Union. 1997. London, U.K.: Macmillan Press Ltd. Especially Chapter 6, Professional interests (pp. 133-154)

HAYNES, D., and COTTON R. 1996. European Library and Information Research policy: proceedings of a seminar held at the Hotel Russell, London, 7 - 9 December 1994. London, U.K.: British Library Research and Development Department (BLR\&D Report 6249)

HAYNES, D. 1996. A summary of research activities in Europe. in: HAYNES, D and COTTON R. 1996. European Library and Information Research policy: proceedings of a seminar held at the Hotel Russell, London, 7 - 9 December 1994. London, U.K.: British Library Research and Development Department, pp 74 - 78 (BLR\&D Report 6249)

HIRSH, W., BURGOYNE, J., and WILLIAMS, S. 2002. The value of business and management education: preliminary findings, October 2002. London, U.K.: Association of Business Schools. Unpublished typescript. [IFLA] 1995. Influencing the decision makers: impact strategies for librarians in developing countries - draft outline of recommendations and conclusions [of the] Official Pre Session Seminar, Ankara, Turkey 18 August 1995. The Hague: International Federation of Library Associations and Institutions. Unpublished typescript. INSTITUTE OF PUBLIC FINANCE. 2003. Public Libraries Benchmarking Club. Viewed on the Web on 3 June 2003 at URL - http://www.ipf.co.U.K./benchmarking/libraries/2003-04/default.asp JOHNSON, I.M. Review of: LANCASTER, F.W. If you want to evaluate your library. (London: Library Association Publishing Ltd., and Urbana: School of Library and Information Science, University of Illinois. 2nd ed. 1993. ISBN 185604083 6) Journal of Librarianship and Information Science, 26 (4), December 1994, 238-239

JOHNSON, I.M. 2000. The role of associations of information and library education in teaching and research: recent and potential developments in Britain and Europe. Education for Information, 18 (3/4), 201-220

JUZNIK, P., and URBANIJA, J. 2002. Developing research skills as an essential knowledge of the profession: experience at the Department of Library and Information Science and Book Studies, University of Ljubljana. Paper presented at: Restructuring LIS education to European standards - a conference organised by EUCLID: the European Association for Library and Information Education and Research, Technological Educational Institution of Thessalonika, Greece, 16 - 19 October. Library Management, 24 (6), August 2003, 324-331 KUHLMAN, S. 1999. Distributed intelligence: combining evaluation, foresight and technology assessment. The IPTS Report, 40, December, 16-22

LEADBETTER, C. 2003. Overdue: how to create a modern public library service. London, U.K.: Demos. (Laser Foundation Report)

LEWIN, K.M. 1993. Education and development: the issues and the evidence. London, U.K.: Department for International Development.

[LEXISNEXIS.] 2003. Ninety-one percent of librarians say shift from 'information gatherer' to 'information consultant' is key to success: LexisNexis nationwide survey reveals that delivering ROI - "Return on Investment" - is information professionals top priority for the future. PRNewswire, 10 June. Viewed on the Web at URL - http://www.prnewswire.com

MARCO, G.A. 1977. A rationale for international library education. International Library Review, 9 (3), July, 355-362

MATARASSO, F. 1998. Beyond book issues: the social potential of library projects. London, U.K.: British Library Research and Innovation Centre. (BLR\&I report 87)

McNICHOL, S., and NANKIVELL, C. 2003. The LIS research landscape: a review and prognosis. Birmingham, U.K.: University of Central England, Centre for Information Research and Teaching. Viewed on the web on 3 July 2003 at URL - www.cie.uce.ac.uk/cirt/projects/past/LISlandscape_final report.pdf MENOU, M.J. 2001. Information impact: progress of IDRC and recent developments. in: Impact Evaluation of services and projects - a Seminar organised by Institute of Information Scientists and Information for Development Forum, London, 6 June 2001. PowerPoint presentation accessed on 3 June 2003 at URL http://nt1.ids.ac.U.K./eldis/iis/IISIFD.ppt

MURPHY, D.F., and RUBIANO, C.I. 1999. Considering the audience: an important phase in project evaluations. in: McKAY, V., and TREFFGARNE, C., editors. Evaluating impact. London, U.K.: Department for International Development. pp.99-106 (Education Research, serial no. 35)

NATIONAL AUDIT OFFICE. 2003. Getting the evidence: using research in policy making - report by the Comptroller and Auditor General. London: The Stationery Office. Viewed on the web on 3 June 2003 at URL - http://www.nao.gov.uk/pn/02-03/0203586.htm 
PEERS I.S., and JOHNSTON, M. 1994. Theory, utility and stakeholders: methodological issues in evaluating a community project on HIV/AIDS in: BOULTON, M. ed. Challenge and innovation: methodological advances in social research on HIV/AIDS. London, U.K.: Taylor and Francis.

RESOURCE. 2003. Impact evaluation programme. Viewed on the web on 3 June 2003 at URL http://www.resource.gov.uk/information/evidence/ev_impev.asp

ROJO, J.M. 2002. Time-scales in the provision of scientific advice: the role of long and medium-term advisory bodies. The IPTS Report, 61, February, 4-8

SAYWELL, D., and COTTON, A. 1999. Spreading the word: practical guidelines for research dissemination strategies. Loughborough, U.K.: Water Engineering and Development Centre

SCHARTINGER, D., RAMMER, C., FISCHER, M.M., and FRÖHLICH, J. 2002. Knowledge interactions between universities and industry in Austria: sectoral patterns and determinants. Research Policy, 31 (3), March, 303-328

SCOTT, A. 1999. The dissemination of environmental research: paper for the European Environment Agency. Brighton, U.K.: University of Sussex, Science Policy Research Unit, p. 11

STREATFIELD, D., and MARKLESS, S. 2002. Critical evaluation of the LIC Value and Impact Programme. London, U.K.: Information Management Associates. Viewed on the Web on 3 June 2003 at URL http://www.resource.gov.U.K./documents/ev_impevb.pdf

TURNER, K.J. 2002. Do information professionals use research published in LIS journals? in: 68th IFLA Council and General Conference, Glasgow, August 18 - 24. The Hague: International Federation of Library Associations and Institutions (Ref. 009-118-E) Viewed on the web on 3 June 2003 at URL http://www.ifla.org/IV/ifla68/papers/009-118e.pdf

WARR, W. 2003. A framework to measure impact. Information World Review, July/August, 8

WATER ENGINEERING AND DEVELOPMENT CENTRE. 2000. Dissemination pathways and indicators of impact on development: a review of literature. Loughborough, U.K.: W.E.D.C. Viewed on the Web on 3 June 2003 at URL - http://www.lboro.ac.U.K./departments/cv/wedc/projects/stw/lr6.pdf

WAVELL, C., BAXTER, G., JOHNSON, I.M., and WILLIAMS, D. 2002. Impact evaluation of museums, archives and libraries: available evidence project. Aberdeen, U.K.: The Robert Gordon University. Viewed on the Web on 3 June 2003 at URL - http://www.resource.gov.U.K./information/evidence/ev_impev.asp WILLIAMS, D.A., WAVELL, C., and COLES, L. 2001. Impact of Secondary School Libraries on attainment and learning: critical literature review: Final report for Department of Education and Skills and Resource: the Council for Museums, Archives and Libraries. Aberdeen, U.K.: The Robert Gordon University. Viewed on the web on 3 June 2003 at URL -

http://www.rgu.ac.U.K./files/Impact\%20of\%20School\%20Library\%20Services1\%2Epdf

WILLIAMS, D.A., COLES, L., and WAVELL, C. 2002. Impact of School Library Services on attainment and learning in primary schools: Final report for Department for Education \& Skills and Resource: the Council for Museums, Archives and Libraries. Aberdeen, U.K.: The Robert Gordon University. Viewed on the web on 3 June 2003 at URL - http://www.rgu.ac.U.K./files/ACF1C8D\%2Epdf

ZIELINSKI, C. 2001. The changing role of information in development. in: Impact Evaluation of services and projects - a Seminar organised by Institute of Information Scientists and Information for Development Forum, London, 6 June 2001. Viewed on the web on 3 June 2003 at URL -

http://www.iwsp.org/The\%20Changing\%20Role\%20of\%20Information\%20in\%20Development.htm

\section{FURTHER READING}

BARRE, R. 1999. Public research programmes: socio-economic impact assessment and user needs. The IPTS Report, 40, December, 5-9

VINCENT, R. 2001. Beyond circles in square boxes: lessons learned from health communication impact evaluations. in: Impact Evaluation of services and projects - a Seminar organised by Institute of Information Scientists and Information for Development Forum, London, 6 June 2001. Viewed on the web on 3 June 2003 at URL - http://www.healthcomms.org/doc/iispaper.doc

\section{AUTHORS}

Ian Johnson is an Assistant Dean in the Aberdeen Business School, responsible inter alia for the Department of Information Management. He is currently joint editor of Libri: international journal of libraries and information services, and a member of the Editorial Board of Education for Information. Professor Dorothy Williams is the Research Coordinator in the Department of Information Management, and was Project Head for the 3 studies 
searching for impact evidence that were undertaken for Resource. Caroline Wavell and Graeme Baxter are the Research Assistants who undertook the critical literature review. 